\title{
Editorial
}

\section{¿Hacia un marketing holístico?}

El mercadeo es una disciplina que ha tenido fuertes cambios en la última década. Los cambios se han originado principalmente por una visión más amplia sobre el rango de actividades que cubre el mercadeo, las variables involucradas en los intercambios, más allá de lo transaccional, y los procesos de gestión que se requieren. Entre los mútiples cambios en la disciplina, se han creado nuevas aproximaciones respecto al comportamiento de compra y consumo, la orientación empresarial hacia los mercados, el manejo de las relaciones con los clientes, la administración de los canales de distribución y comunicación (medios) y la forma como se puede involucrar al consumidor en el diseño de los productos y de las estrategias. Estos cambios han llevado a conceptos como CRM (Custormer relastioship management), administración de categorías, personalización del producto y la oferta, y al concepto general de creación de valor al cliente. Aunque estos cambios marcan una tendencia más profesional del hacer en mercadeo, no han logrado una variación real en la concepción de lo que es el marketing. Ante este vació surgen una serie de propuestas que van más allá de la función empresarial del mercadeo, a la concepción del mercadeo holístico.

El marketing holístico plantea una serie de interrogantes y alternativas al mercadeo estratégico tradicional, en primer lugar, por la limitación del enfoque del mercadeo estratégico para incorporar al consumidor en las diferentes etapas de la gestión de marketing. En segundo lugar, por el papel de la identificación, la creación y la entrega de valor al cliente dentro de un proceso único y continuo del mercadeo, más que de etapas separadas. En tercer lugar, por el concepto de plataforma estratégica, que da cabida a las interacciones de mercadeo en diferentes procesos y con diferentes fuerzas.

El mercadeo holístico requiere ser estudiado desde una óptica más profunda que la de la tradicional visión de un sistema en dos etapas, el estratégico y el táctico; también incita al replanteamiento de estructuras organizativas funcionales para pasar a estructuras centradas en procesos, en los que la base del trabajo es la cooperación entre áreas, divisiones y colectivos. El mercadeo holístico también amplía la visión del gestor de marketing porque le impone la necesidad de integrar los componentes estratégicos de cada plataforma, además integra transversalmente la estrategia de marketing con la estrategia corporativa. El mercadeo holístico hace evidencia de la complejidad de la gestión de marketing y la necesidad de apoyarse más y mejor con tecnologías de información y comunicación apropiadas.

Son muchas las dudas no despejadas por el modelo holístico, por lo cual se requiere hacer un planteamiento serio de algunos temas que no fueron tratados a profundidad por sus autores, así surge este escrito en donde los profesores Clemencia Godoy, Juan Manuel Cárdenas y Ricardo Ariza interrogan el modelo sobre los problemas de la innovación, la gestión del marketing apoyada en tecnologías de información y los procesos de comunicación organizacional.

Este documento es un aporte para los académicos y profesionales que estén interesados en profundizar en las posibilidades de un nuevo enfoque holístico e integral del mercadeo. Los planteamientos aquí incluidos se convierten en cuestionamientos para la gestión contemporánea del mercadeo y por lo tanto, en un invaluable aporte para el desarrollo de la disciplina del mercadeo. Que lo disfuten.

\section{Diana Forero \\ Directora de investigación \\ Facultad de Ciencias de la Comunicación y Artes Politécnico Grancolombiano}

